\title{
Examining the Impact of the Walking School Bus With an Agent-Based Model
}

| Yong Yang, PhD, Ana Diez-Roux, PhD, Kelly R. Evenson, PhD, and Natalie Colabianchi, PhD

We used an agent-based model to examine the impact of the walking school bus (WSB) on children's active travel to school. We identified a synergistic effect of the WSB with other intervention components such as an educational campaign designed to improve attitudes toward active travel to school. Results suggest that to maximize active travel to school, children should arrive on time at "bus stops" to allow faster WSB walking speeds. We also illustrate how an agent-based model can be used to identify the location of routes maximizing the effects of the WSB on active travel. Agent-based models can be used to examine plausible effects of the WSB on active travel to school under various conditions and to identify ways of implementing the WSB that maximize its effectiveness. (Am J Public Health. 2014;104:1196-1203. doi:10.2105/AJPH. 2014.301896)

Active travel to school (ATS) is of special significance to children's physical and mental health and has important implications for the environment and sustainable development., ${ }^{1,2}$ Today, fewer than $15 \%$ of US children and adolescents walk or bicycle to school, compared with approximately 50\% half a century ago. ${ }^{3}$ Multiple factors are associated with ATS, including characteristics of children and families as well as features of schools and neighborhoods. $^{1,4}$

Existing interventions designed to promote ATS are heterogeneous in terms of size, scope, and focus, ${ }^{5-7}$ and according to a recent systematic review, ${ }^{8}$ most have shown limited effectiveness in promoting ATS. Interventions targeting schools, parents, and communities and those geared toward a specific goal tend to be more effective than those that are broader in focus. The ability to evaluate an intervention's impact has often been limited by methodological issues such as lack of an experimental study design and limitations in the validity and reliability of the measures used. The complexity of the factors influencing ATS and the fact that the effects of these factors may vary from context to context further limit the utility of both observational and experimental studies in evaluating the long-term impact of various interventions.

One notable example of an intervention to increase ATS is the walking school bus (WSB). ${ }^{9}$ The WSB is a program in which children walk to school in groups led by adults along a planned route with designated meeting places (i.e., "bus stops") where other children join in. The primary goal is to allow children to actively and safely commute to school. During the 2009-2010 school year, about $6.2 \%$ of the elementary schools in the United States organized a WSB. ${ }^{10}$ Although most WSBs have shown promising short-term benefits, ${ }^{7,11-15}$ evidence of their effectiveness over long periods is limited.

A major challenge in evaluating the impact of interventions such as the WSB is that it is difficult to evaluate how the intervention may interact with features of the context in which it is implemented or how features of the intervention may influence its effectiveness. For example, the effects of ATS may be modified by educational campaigns targeted at increasing favorable attitudes toward walking among children.

Various features related to how the WSB is implemented may also influence its effectiveness. When using the WSB, children may take longer to arrive at school because of the waiting time at the "bus stop," the group's decreased walking speed, and detours that need to be taken for the child to reach the WSB route. If children arrive at the stop earlier (increasing their waiting times), group walking speed can increase (because the group is less likely to wait at each stop for other children to join in), reducing the total travel time. The challenge is to find the strategy that minimizes waiting time while maximizing walking speed.

Another challenge for the WSB is the selection of bus routes and stops. More bus routes may attract more children to join the WSB but may also necessitate more adult involvement. It is therefore important to identify the most beneficial placement of a limited number of bus routes. To our knowledge, there is scant information on how these contextual or implementation factors could affect the impact of the WSB on children's active travel to school.

A large body of work has recommended multilevel interventions (i.e., interventions that combine environmental and individual-level elements) for behavioral change because of possible synergistic effects. ${ }^{16-20}$ It has been noted that evidence on interventions derived from randomized trials is often limited because the impact of context as a modifier cannot be investigated. For example, it is well established that physical activity is influenced by the interplay between environmental and psychological factors. ${ }^{21,22}$ Yet, existing observational or experimental studies are ill suited to investigate these interactions. Modeling or simulation studies can be important sources of complementary evidence on how the impact of interventions such as the WSB may be affected by various contextual factors.

In public health, there has been growing interest in using complex systems modeling as a complement to observational studies and randomized trials to better understand the plausible impact of interventions or policies in different contexts. ${ }^{23-25}$ The tools of complex systems models allow researchers to evaluate the effects of interventions while accounting for dependencies and feedbacks, which are not easily captured in standard statistical analyses. One such tool is agent-based modeling. Agent-based models (ABMs) are computational models that can be used to simulate the actions and interactions of agents as well as the dynamic interactions between agents and their environments to gain an understanding of the 
functioning of a system. ${ }^{26,27} \mathrm{ABMs}$ have increasingly been used to investigate how the social and built environments shape people's travel behavior. ${ }^{28-32}$

We previously developed an $\mathrm{ABM}^{31}$ to simulate children's ATS within a hypothetical city. The model was used to explore the plausible implications of policies targeting 2 established barriers to ATS: long distance to school and traffic safety. In this study, we extended the model to examine the potential effects of the WSB on ATS. Specifically, we examined whether the effects of the WSB are enhanced by an educational campaign aimed at improving attitudes toward ATS among children, how changing the walking speed of the WSB and the waiting time for children at the WSB stops affects ATS, and the impact of different bus route placements. All 3 issues are important in the design and implementation of the WSB but are difficult to assess in experimental or observational studies. Because previous work suggested that ATS is influenced by population density, ${ }^{31}$ we investigated the 3 issues across various levels of population density.

\section{METHODS}

Our ABM of children's travel to school was based on a theoretical and empirically informed conceptual model of the factors that influence school travel mode choice in children. ${ }^{1,4,31,33-38}$ We included only key elements and made no attempt to incorporate all possible influences on travel mode choice, which would have made the model difficult to evaluate and would have detracted from its ability to provide insight into fundamental dynamics. The goal was not to predict ATS in a specific context but, rather, to gain insight into the factors that affect the WSB under different real-world conditions. These insights can later be tested empirically via other studies and analytical approaches.

Our previously developed ABM on active travel was adapted to incorporate the WSB. We describe only key elements of the model here (additional details have been reported elsewhere $^{31}$ ). The model, developed in Java and Repast, ${ }^{39}$ represented a hypothetical city with a grid-shaped road network, different numbers of households (based on different scenarios), and 4 elementary schools. Each household included a single child, and each child was enrolled in 1 of the 4 schools. The city was divided into 4 school zones of equal size, with 4 schools located at the center of each zone, and children were enrolled in the school within their zone.

Each household had an assigned level of concern toward traffic safety with respect to children walking to school, and each child had an assigned attitude toward ATS. A random draw from a uniform distribution between 0 and 1 was used in assigning both variables at model initialization. Two dynamic processes suggested by empirical work were included in the model. ${ }^{40-48}$ First, traffic safety on roads is a function of the total number of people who walk; that is, more people walking increases the level of traffic safety. Previous studies have suggested that increased walking and bicycling may help improve traffic safety. ${ }^{40-42} \mathrm{~A}$

a

b

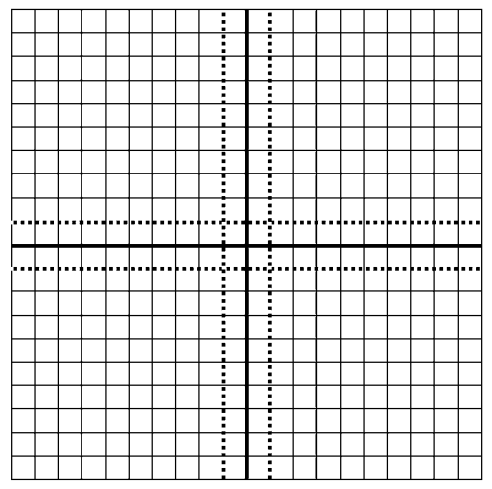

C

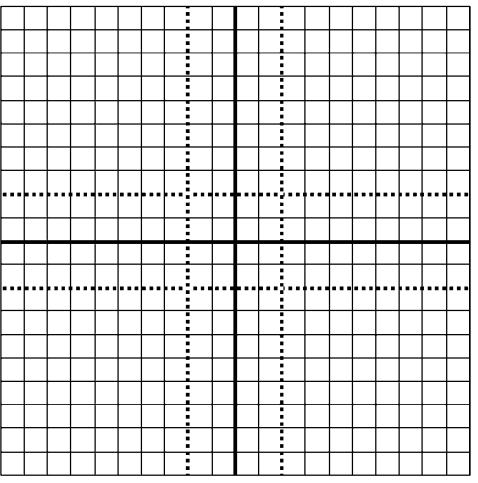

d
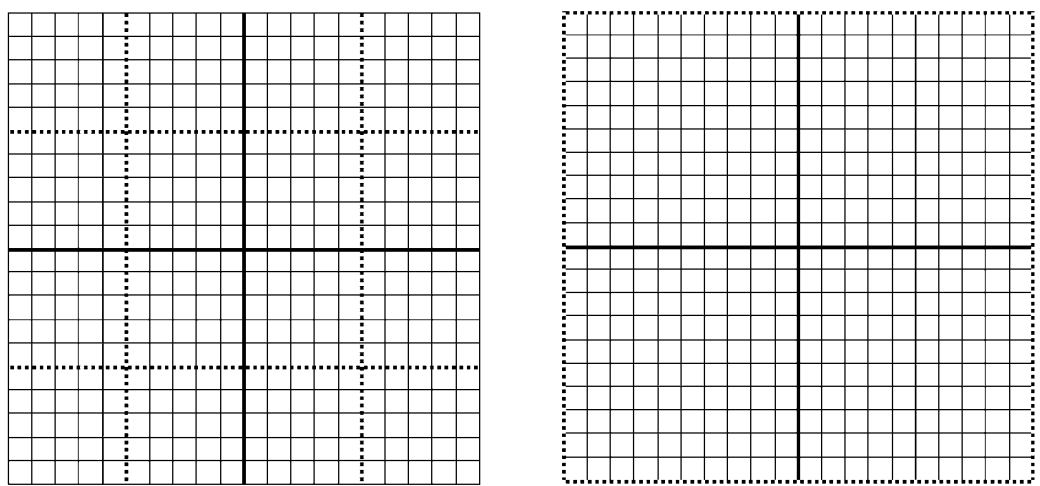

Note. The school is located in the center of the grid, where the 2 dark-lined streets cross. The 2 dark lines are the bus routes in the baseline scenario, and the 4 dashed lines are examples of placements of additional routes.

FIGURE 1-Street network for a single school zone with distance between the existing and additional routes of (a) 1 block, (b) 2 blocks, (c) 5 blocks, and (d) 10 blocks. 
shown with dark lines in Figure 1). Because the children walked together with adults along the WSB route, the safety level on the bus routes was set to 1, the highest model value for safety.

Each day, children considered travel options according to the following sequence: joining the WSB, walking on their own, and being driven. The WSB was considered first. A child joined the WSB if the value assigned for safety along the route was above the value assigned for household concern regarding traffic safety (by definition, the safety level along the WSB portion of the route was set to the highest value, as noted) and if the value for child's attitude toward ATS was higher than a threshold value that depended on the distance to the school along the WSB route (the WSB route might necessitate a detour from the most direct route that the child would normally take if he or she walked alone) and the additional time needed for the trip (to accommodate waiting times for the WSB, the possibility of slow walkers in the group, and the need to wait for other children at later stops).

Children who did not join the WSB would subsequently consider walking on their own, with the same 2 conditions but possibly a route different from that of the WSB. Generally, in the case of children walking on their own, the first condition (safety concerns) was less likely to be met than with the WSB because of the higher degree of safety along the WSB route, whereas the second condition (attitude) was more likely to be met because of the longer distance to school along the WSB route and the impact of waiting times and slower walking speeds. We selected safety and distance as the main factors influencing travel mode choice because safety concerns and long distances to school have been identified as key barriers to ATS among children in the United States. ${ }^{49}$ Children who neither joined the WSB nor walked on their own were driven to school.

The 3 issues noted earlier (whether the impact of the WSB is enhanced by an educational campaign aimed at improving children's attitudes toward ATS, how changing walking speeds and waiting times influences ATS, and the impact of different bus routes) were explored for different levels of population density (scenarios with 1000, 2000, 4000, 8000, and 16000 total households in the city or, equivalently, 250, 500, 1000, 2000, and 4000 students per school). The percentages of children who walked to school were compared across the different scenarios.

\section{Effects of an Educational Campaign}

To test the independent and synergistic effects of the WSB and an educational campaign, we compared the impact on active travel of improving attitudes toward ATS (by adding 0.1 to the attitude toward ATS value for each child (in the baseline scenario, the mean attitude value was set to 0.5), implementing the WSB, and combining these 2 interventions. We also explored whether the WSB effect was modified by the mean attitude toward ATS in the population (ranging from 0.2 to 0.8 at intervals of 0.1 ).

\section{Effects of Walking Speed and Waiting Time}

We explored the effects of reducing the waiting time for each child at the bus stop from 5 to 0 minutes, the effects of increasing the walking speed of the WSB (for ratios of WSB speed to single child walking speed ranging from 0.5 to 1 ), and the combination of reducing the waiting time and increasing the walking speed (with waiting times ranging from 0 to 5 minutes and speed ratios ranging from 0.5 to 0.9 ).

\section{Effects of Different Bus Route \\ Placements}

We assumed that an additional set of WSB bus routes could be added to the existing routes
(Figure 1 shows the sample scenarios compared). We contrasted a range of placement scenarios (shown in panels a through $\mathrm{c}$ of Figure 1), with the new routes being placed at increasing distances from the original routes (each scenario was labeled 1-10 according to the number of blocks between the original and new bus routes). The goal was to identify where bus route placement would maximize the effect of the WSB on ATS.

\section{RESULTS}

As can be seen in Table 1, in the baseline model without the WSB, a higher population density was associated with a higher percentage of children walking to school. The implementation of the WSB resulted in a higher percentage of children using ATS; increases were greater in areas with lower population densities, such that only small differences in ATS remained across levels of population density after implementation of the WSB. Improving attitudes toward active travel was also associated with increases in the percentage of children using ATS. These effects were greater at higher population densities. When the 2 elements (WSB and improved attitudes toward ATS) were combined, the increase in ATS was larger than the sum of the effects of the 2 elements separately, with the synergistic effect being greater at lower population densities.

Figure 2 shows the effects of the WSB on active travel for different mean attitudes toward ATS and different population densities.

\begin{tabular}{|c|c|c|c|c|}
\hline $\begin{array}{c}\text { School } \\
\text { Population }\end{array}$ & $\begin{array}{l}\text { Children Using } \\
\text { ATS Without } \\
\text { WSB, \% }\end{array}$ & $\begin{array}{c}\text { Children } \\
\text { Using ATS } \\
\text { With WSB, \% }\end{array}$ & $\begin{array}{l}\text { Children Using ATS } \\
\text { With Educational } \\
\text { Intervention, \% }{ }^{\mathrm{a}}\end{array}$ & $\begin{array}{c}\text { Children Using ATS } \\
\text { With Both WSB and } \\
\text { Educational Intervention, \% }\end{array}$ \\
\hline 250 & 7.6 & 15.1 & 12.7 & 23.1 \\
\hline 500 & 9.3 & 15.2 & 16.0 & 23.7 \\
\hline 1000 & 11.6 & 15.7 & 19.6 & 24.7 \\
\hline 2000 & 13.6 & 16.2 & 22.7 & 25.8 \\
\hline 4000 & 15.1 & 16.7 & 25.0 & 26.9 \\
\hline
\end{tabular}

Note. ATS = active travel to school; WSB = walking school bus.

an this scenario, each child's attitude value (range $=0-1$ ) was increased by 0.1 (with higher values indicating that the child is more likely to engage in ATS). In the baseline scenario, the mean population value was 0.5 . 
a

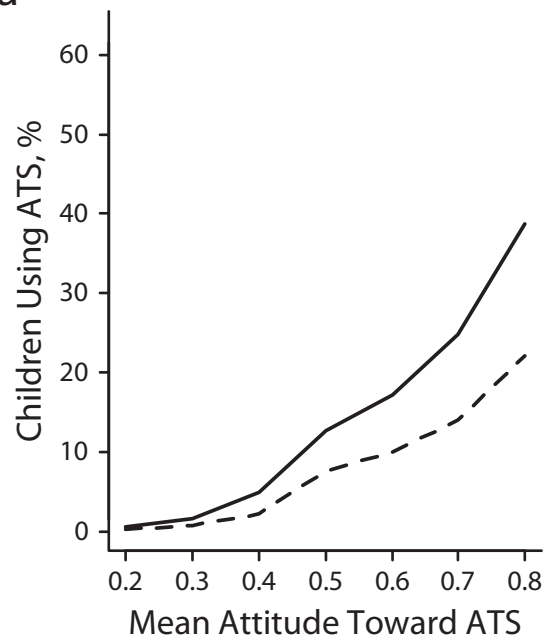

d

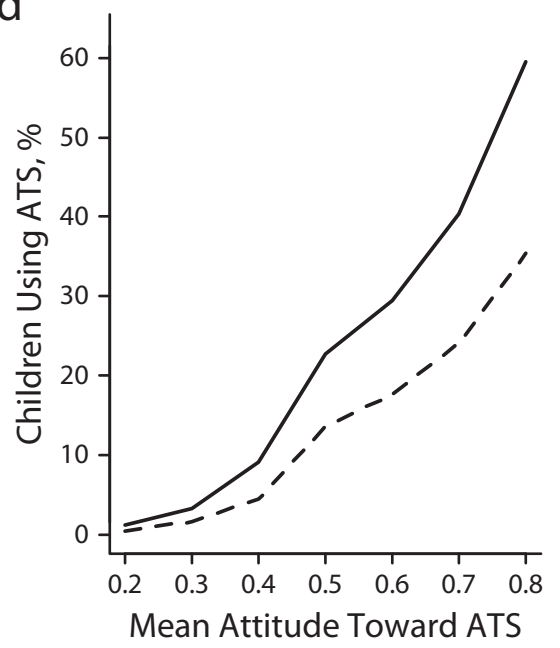

b

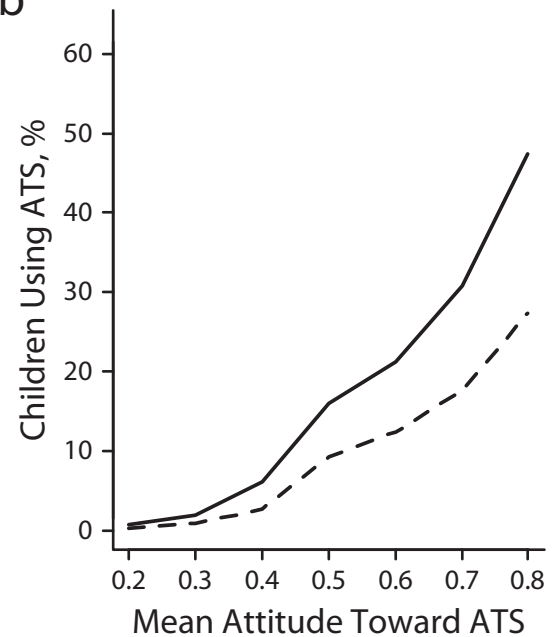

e

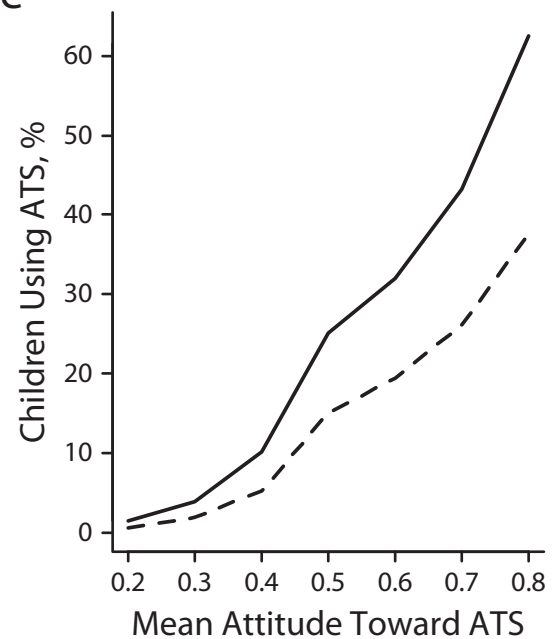

C

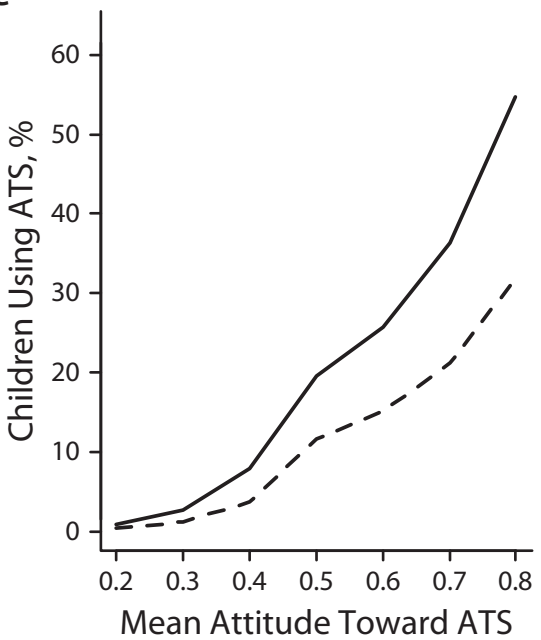

- - - With WSB Without WSB

FIGURE 2-Percentages of children engaging in active travel to school (ATS) with and without the walking school bus (WSB), by mean attitude toward ATS value and school population density of (a) 250 students, (b) 500 students, (c) 1000 students, (d) 2000 students, and (e) 4000 students.

The WSB was increasingly effective when the mean attitude toward ATS in the population increased from a value of 0.2 to 0.5 . However, within the range of 0.6 to 0.8 , the effectiveness of the WSB was almost unchanged. This pattern was similar for all population densities.

Figure 3 shows the effects of WSB waiting time and walking speed on ATS. Reductions in waiting time and increases in WSB speed were associated with increases in the effects of the WSB on active traveling, and these effects were smaller at higher population densities. Within the range of WSB waiting times and speeds that we investigated, increases in speed were more influential than reductions in waiting time in increasing the effects of the WSB on active travel, especially at lower population densities (as shown by the steeper curves in Figure 3a than in Figure 3b).

As can be seen in Figure 4 (with 1000 students in each school), waiting time and walking speed jointly affected the increase in ATS associated with implementation of the WSB. Greater decreases in walking speed necessitated shorter waiting times to achieve the same effect on ATS. For example, as highlighted by the horizontal line in Figure 4, the same ATS percentage can be achieved with a waiting time of 0 minutes and a 30\% reduction in WSB speed (ratio of 0.7) as with a higher walking speed (ratio of 0.9) and waiting times as long as 5 minutes. These patterns were similar for the other population densities (data not shown).

Figure 5 shows the impact on ATS of 10 alternate bus route placements. The WSB was most effective when the additional group of bus routes was placed 1 block $(200 \mathrm{~m})$ or 2 blocks $(400 \mathrm{~m})$ away from the existing routes (the streets shown with dashed lines in Figure $1 \mathrm{a}$ and $1 \mathrm{~b}$, respectively). When the distance was 10 blocks from the existing routes, the additional group of bus routes had no added value (as can be seen from a comparison of the percentages in Figure 5 and Table 1). 

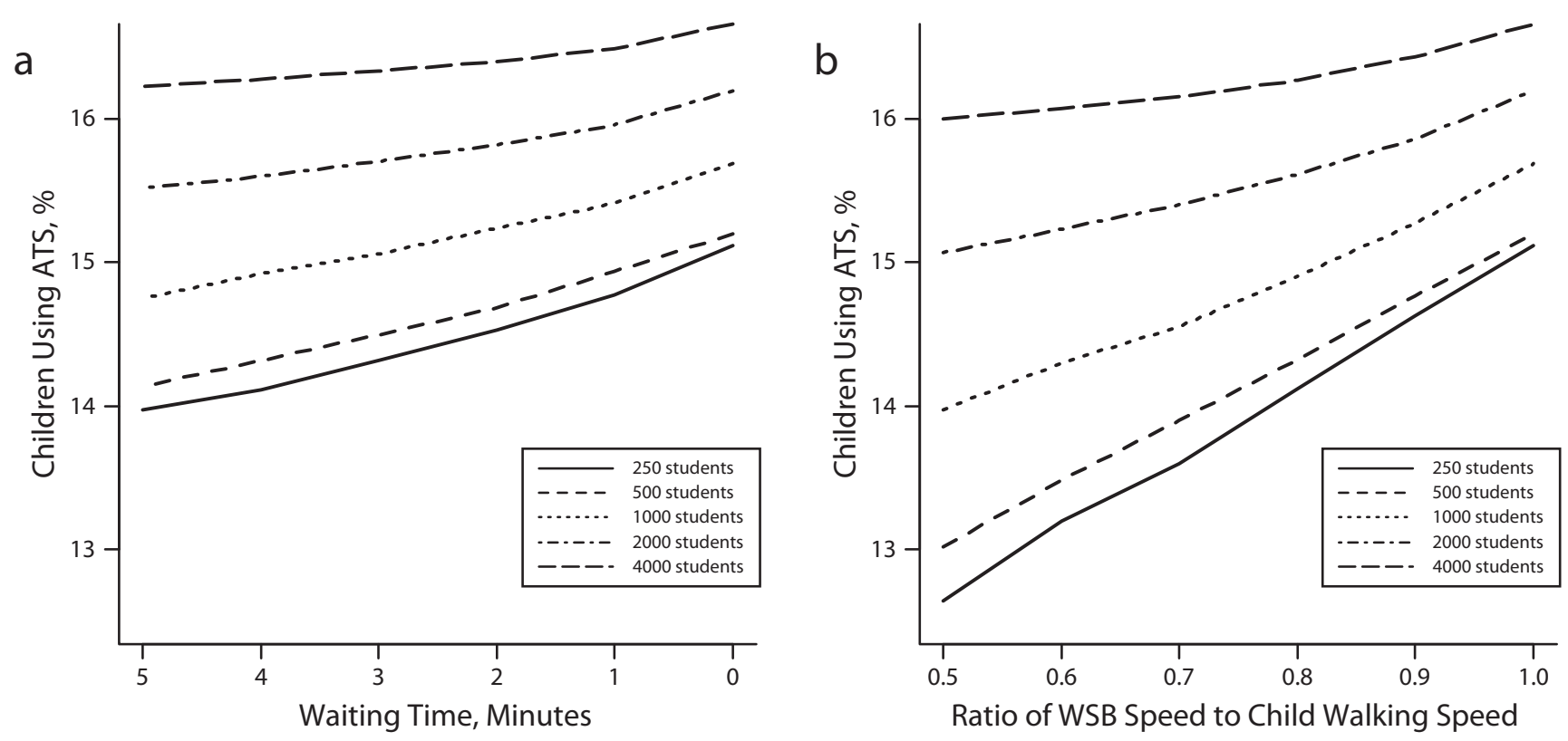

Note. Percentages were computed for 5 different school population densities (250, 500, 1000, 2000, and 4000 students). For ratios of WSB speed to child walking speed, higher ratios represent faster walking speeds.

FIGURE 3-Percentages of children engaging in active travel to school (ATS), by population density, under the 2 walking school bus (WSB) scenarios (a) reduced waiting time and (b) increased walking speed.

\section{DISCUSSION}

We used agent-based modeling to examine the potential impact of the walking school bus on ATS under various conditions to gain insight into how the beneficial effects of the WSB could be maximized. The WSB was more effective in areas with lower population densities. We identified a synergistic effect of the WSB in combination with interventions such as educational campaigns that enhance attitudes toward ATS. We also showed that effectiveness of the WSB was influenced by the mean attitude toward ATS in the population. On a more practical level, our results suggest that children should be encouraged to arrive at bus stops on time to allow faster WSB walking speeds (i.e., having children wait for the bus is better than having the bus wait for children). We also illustrated how an ABM can be used to identify the locations of bus routes that maximize the effects of the WSB on active travel.

Consistent with results previously reported, ${ }^{31}$ higher population densities were associated with higher percentages of ATS because the higher absolute number of walkers increased the safety level on streets. As noted, the WSB was more effective in locations with lower population densities, such that variations in ATS across levels of population density almost disappeared after WSB implementation. The reason is that, under the assumptions of our model, a key benefit of the WSB is an improvement in safety levels (the safety levels of the WSB route were set to the highest level). Overall, areas with lower population densities benefited more from the WSB because the impact of creating a safe walking route was greatest in these areas (where overall safety levels were lower).

The WSB and increases in positive attitudes toward active travel had synergistic effects on ATS. These effects occurred because, in this model, 2 conditions (safety concerns and improved attitudes toward ATS) had to be met for a child to choose ATS. The WSB and educational interventions helped improve safety and attitudes toward ATS, respectively. When one of 2 interventions is implemented, the pool of children for whom only a single condition remains to be met is increased, and thus the effectiveness of the second intervention is magnified. This suggests that, if effects are to be maximized, implementations of the WSB should be accompanied by simultaneous campaigns to improve attitudes toward ATS.
The WSB effects were modified by attitudes toward ATS within the population. The 0.5 value for mean attitude toward ATS was a tipping point: for attitudes below this value, higher means resulted in enhanced effectiveness of the WSB; for attitudes above this value, the level of effectiveness was relatively stable. These results again suggest that interventions designed to improve attitudes toward ATS should be implemented as a prerequisite to implementation of the WSB. The community action model ${ }^{50}$ supports the idea that efforts related to preparation, promotion, programming, policy, and physical elements are all important to the success of these types of interventions.

Under the assumptions in our model, increases in WSB speed enhanced the impact of the WSB on ATS more than reductions in waiting times. The implication is that children should be encouraged to arrive at bus stops in time to avoid slowing down the WSB. However, our conclusion regarding the relative importance of waiting time and WSB speed is contingent on whether the ranges we compared are realistic. Drawing firm conclusions would require real data on reasonable ranges with respect to children's walking speeds, group 


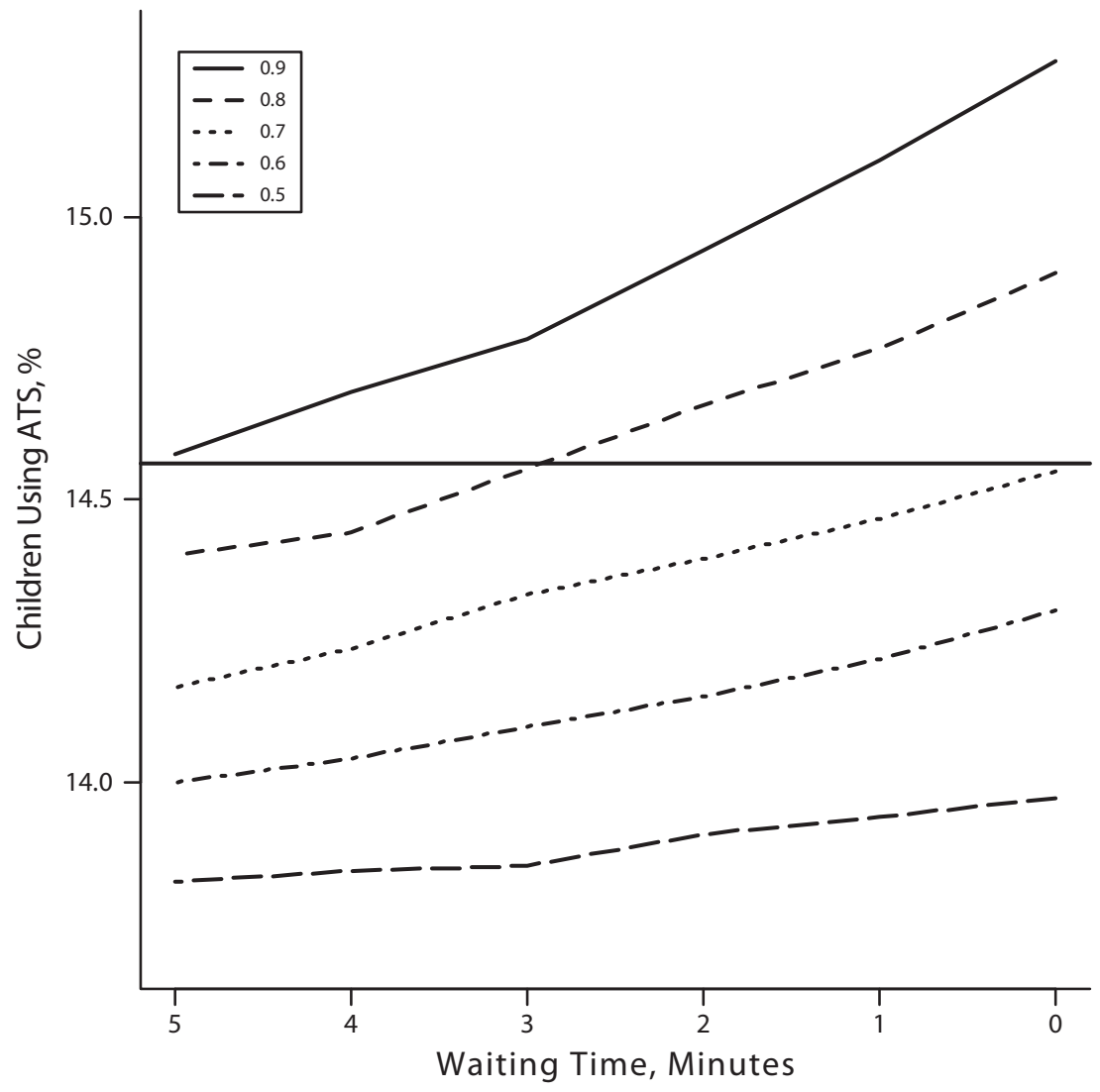

Note. Percentages are based on a school population of 1000 students. Higher ratios represent faster walking speeds.

FIGURE 4-Percentage of children using active travel to school (ATS) when the walking school bus is implemented for combinations of waiting times and walking speeds.

walking speeds, and the correlation between group walking speeds and children's waiting time.

Another caveat is that we used the same distance decay parameters for scenarios including and omitting the WSB; that is, we assumed that distance has the same influence on children's desire to walk regardless of whether they are walking alone or in groups. In reality, when children walk together, they may be happier to walk longer distances than when they walk alone. Our model did not explicitly account for the presence of school buses; however, given that our primary interest was in understanding the primary factors influencing active travel, we did not necessarily need to differentiate school buses from other forms of motorized travel (although research questions differing from those examined here may require incorporation of this travel mode).
The percentage of ATS was found to peak when the additional group of bus routes was located 2 blocks away from the school. If the additional group of bus routes is too close to the existing routes, they will overlap with each other in terms of attracting children. However, if the additional group of bus routes is too far from the school, it is less likely to be effective because although safety levels are improved, the distance involved becomes an important barrier to children living close to the new routes.

Of course, real street networks are far more complicated than the simple grid used in our model. For example, there are important differences between conventional modern suburban layouts and older cities' traditional layouts ${ }^{51}$ that could have implications for the effectiveness of the WSB. There may also be shortcuts available to walkers across parks or through buildings that are not available with other transportation modes. In addition, when selecting the most appropriate route for the WSB, one should consider the distribution of the student population as well, which may be different from the random distribution assumed in our model.

Our results are based on a theoretical model of travel mode choice among children that we believe includes several fundamental influence factors and processes. More details could be added to the model if they were judged to be fundamental to the process or key to answering a specific research question. For example, psychological properties such as travel habits could be added. A child may become habituated to a certain travel mode and may tend to repeat the same mode if there are no significant changes in family, school, built, or social environments. In addition, the model could be modified to include assessments of other travel modes (i.e., public transportation or bicycling) or to explore variations in attitudes and travel behaviors according to age, gender, income level, and environment. ${ }^{31}$

The model can also be tailored to specific real cases to further explore its potential and answer questions relevant to real-world conditions. This requires the model to be empirically grounded, that is, informed by data relevant to the specific context. A limitation of our model is that we assume that all households use the same set of rules to select their travel mode; in reality, however, these rules may vary according to factors such as the child's age and the family's income level. If data supporting differences in rules are available, the model can be modified to incorporate this type of heterogeneity.

In summary, we found that the WSB can interact synergistically with educational interventions. Our model illustrates how the effectiveness of the WSB in increasing ATS among children is affected by route placement, waiting times, and speed. The model provides a starting point for efforts to explicitly account for dynamic interactions between individuals and environments. It can be refined in terms of structure and parameter values as additional data on related factors and processes become available. Finally, the valuable insights derived from the model can be further assessed in 


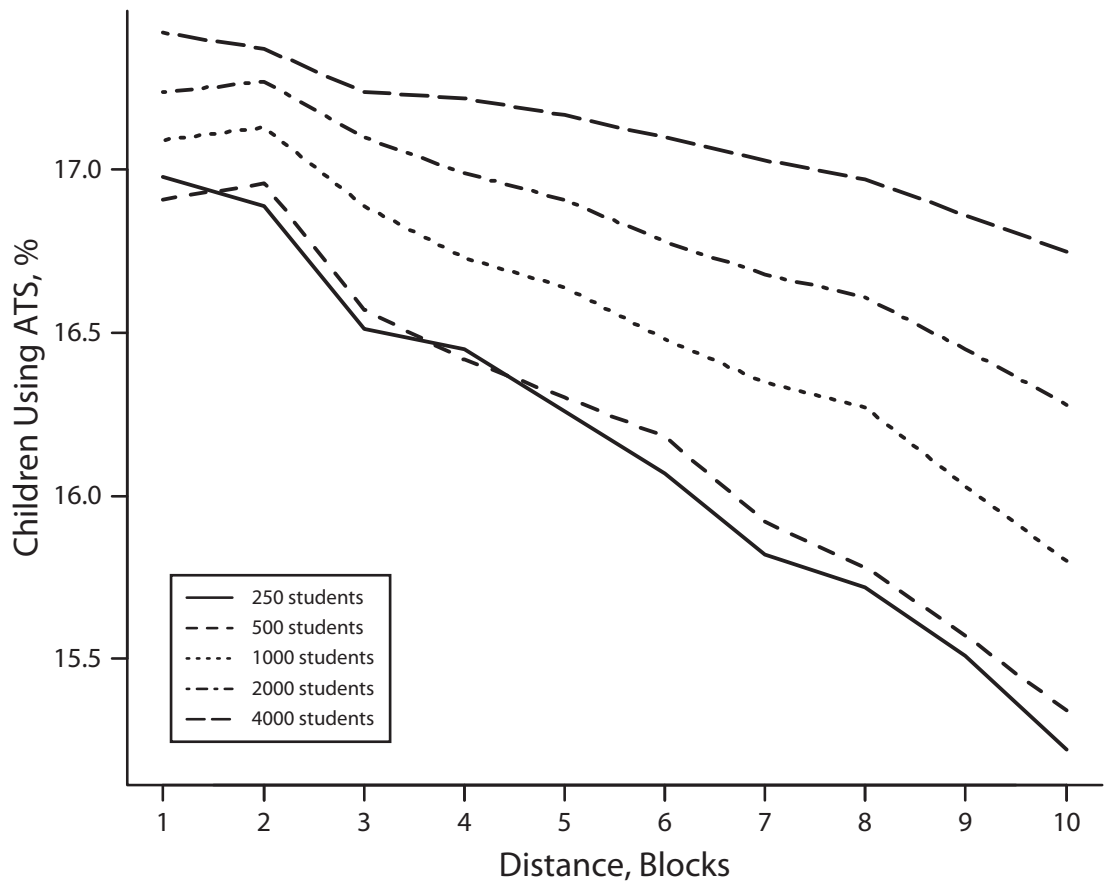

Note. One block $=200$ meters.

\section{FIGURE 5-Percentages of children engaging in active travel to school (ATS) in a scenario} involving 10 alternate walking school bus route placements, by school population density.

future empirical studies on the effectiveness of the WSB.

\section{About the Authors}

At the time of this study, Yong Yang and Ana Diez-Roux were with the Department of Epidemiology, School of Public Health, University of Michigan, Ann Arbor. Kelly R. Evenson was with the Department of Epidemiology, School of Public Health, University of North Carolina at Chapel Hill. Natalie Colabianchi was with the Institute for Social Research, University of Michigan, Ann Arbor.

Correspondence should be sent to Yong Yang, PhD, Department of Epidemiology, School of Public Health, University of Michigan, Ann Arbor, MI 48109 (e-mail: yangyong712@hotmail.com).Reprints can be ordered at http://www.ajph.org by clicking the "Reprints" link.

This article was accepted January 17, 2014.

\section{Contributors}

Y. Yang originated the study, designed and implemented the model, performed the data analysis, and drafted the article. A. Diez-Roux, K. R. Evenson, and $\mathrm{N}$. Colabianchi helped to interpret the results and draft the article.

\section{Acknowledgments}

This research was funded by the National Heart, Lung and Blood Institute (grants R21-HL106467 and R01HL071759) and the Office of Behavioral and Social Sciences Research (grant HHSN276200800013C).

\section{Human Participant Protection}

No protocol approval was needed because no human participants were involved.

\section{References}

1. Davison KK, Werder J, Lawson C. Children's active commuting to school: current knowledge and future directions. Prev Chronic Dis. 2008;5(3):A100.

2. Schoeppe S, Duncan MJ, Badland H, Oliver M, Curtis C. Associations of children's independent mobility and active travel with physical activity, sedentary behaviour and weight status: a systematic review. J Sci Med Sport. 2013;16(4):312-319.

3. McDonald NC, Brown AL, Marchetti LM, Pedroso MSUS. School travel, 2009: an assessment of trends. $A m$ J Prev Med. 2011;41(2):146-151.

4. Lee M, Orenstein M, Richardson M. Systematic review of active commuting to school and children's physical activity and weight. J Phys Act Health. 2008; 5(6):930-949

5. Mendoza J, Levinger D, Johnston B. Pilot evaluation of a walking school bus program in a low-income, urban community. BMC Public Health. 2009;9(1):122.

6. Boarnet G, Anderson C, Day K. Evaluation of the California Safe Routes to School legislation: urban form changes and children's active transportation to school. Am J Prev Med. 2005;28(suppl 2):134-140.

7. Heelan K, Abbey B, Donnelly J, Mayo M, Welk G. Evaluation of a walking school bus for promoting physical activity in youth. J Phys Act Health. 2009;6(5):560-567.
8. Chillón P, Evenson KR, Vaughn A, Ward DS. A systematic review of interventions for promoting active transportation to school. Int J Behav Nutr Phys Act. 2011;8(1):10

9. Walking school bus. Available at: http://www. walkingschoolbus.org. Accessed April 5, 2014.

10. Turner L, Chriqui J, Chaloupka F. Walking school bus programs in US public elementary schools. J Phys Act Health. 2013;10(5):641-645.

11. Mackett RL, Lucas L, Paskins J, Turbin J. A methodology for evaluating walking buses as an instrument of urban transport policy. Transp Policy. 2003;10 (3):179-186

12. McKee R, Mutrie N, Crawford F, Green B. Promoting walking to school: results of a quasi-experimental trial. J Epidemiol Community Health. 2007;61(9):818-823. 13. Staunton CE, Hubsmith D, Kallins W. Promoting safe walking and biking to school: the Marin County success story. Am J Public Health. 2003;93(9):1431-1434 14. Kong AS, Sussman AL, Negrete S, Patterson N, Mittleman R, Hough R. Implementation of a walking school bus: lessons learned. J Sch Health. 2009;79(7): 319-325.

15. Mendoza JA, Watson K, Baranowski T, Nicklas TA, Uscanga DK, Hanfling MJ. The walking school bus and children's physical activity: a pilot cluster randomized controlled trial. Pediatrics. 2011;128(3):e537-e544.

16. Weiner BJ, Lewis MA, Clauser SB, Stitzenberg KB. In search of synergy: strategies for combining interventions at multiple levels. J Natl Cancer Inst Monogr. 2012;44: 34-41.

17. Sallis JF, Owen N, Fisher EB. Ecological models of health behavior. In: Glanz K, Rimer B, Viswanath K, eds Health Behavior and Health Education: Theory, Research, and Practice. San Francisco, CA: Jossey-Bass; 2008:465-482

18. McLeroy K, Bibeau D, Steckler A, Glanz K. An ecological perspective on health promotion programs. Health Educ Q. 1988;15(4):351-377.

19. McLeroy KR, Norton BL, Kegler MC, Burdine JN Sumaya CV. Community-based interventions. Am J Public Health. 2003;93(4):529-533.

20. Stokols D, Allen J, Bellingham RL. The social ecology of health promotion: implications for research and practice. Am J Health Promot. 1996;10(4):247-251

21. Spence JC, Lee RE. Toward a comprehensive model of physical activity. Psychol Sport Exerc. 2003;4(1):7-24.

22. King A, Stokols D, Talen E, Brassington G,

Killingsworth R. Theoretical approaches to the promotion of physical activity: forging a transdisciplinary paradigm. Am J Prev Med. 2002;23(suppl 2):15-25

23. Luke DA, Stamatakis KA. Systems science methods in public health: dynamics, networks, and agents. Annu Rev Public Health. 2012;33:357-376.

24. Diez Roux AV. Complex systems thinking and current impasses in health disparities research. $\mathrm{Am} \mathrm{J}$ Public Health. 2011;101(9):1627-1634.

25. Galea S, Riddle M, Kaplan GA. Causal thinking and complex system approaches in epidemiology. Int I Epidemiol. 2010;39(1):97-106

26. Axtell R, Epstein JM. Agent-based modeling: understanding our creations. Available at: http://www. project2061.org/publications/designs/online/pdfs/ reprints/2_axteps.pdf. Accessed April 5, 2014. 
27. Bonabeau E. Agent-based modeling: methods and techniques for simulating human systems. Proc Natl Acad Sci U S A. 2002;99(suppl 3):7280-7287.

28. Lu Y, Kawamura K, Zellner M. Exploring the influence of urban form on work travel behavior with agent-based modeling. Transportation Res Rec. 2008; 2082:132-140.

29. Yang Y, Diez Roux AV, Auchincloss AH, Rodriguez DA, Brown DG. A spatial agent-based model for the simulation of adults' daily walking within a city. Am J Prev Med. 2011;40(3):353-361.

30. Yang Y, Diez Roux AV, Auchincloss AH, Rodriguez DA, Brown DG. Exploring walking differences by socioeconomic status using a spatial agent-based model. Health Place. 2012;18(1):96-99.

31. Yang Y, Diez-Roux A. Using an agent-based model to simulate children's active travel to school. Int J Behav Nutr Phys Act. 2013;10(1):67.

32. Zhu W, Nedovic-Budic Z, Olshansky RB, et al. Agent-based modeling of physical activity behavior and environmental correlations: an introduction and illustration. J Phys Act Health. 2013;10(3):309-322.

33. Trapp GSA, Giles-Corti B, Christian HE, et al. Increasing children's physical activity: individual, social, and environmental factors associated with walking to and from school. Health Educ Behav. 2012;39(2):172-182.

34. Mammen G, Faulkner G, Buliung R, Lay J. Understanding the drive to escort: a cross-sectional analysis examining parental attitudes towards children's school travel and independent mobility. BMC Public Health. 2012;12(1):862.

35. McMillan TE. Urban form and a child's trip to school: the current literature and a framework for future research. J Plann Lit. 2005;19(4):440-456.

36. McMillan TE. The relative influence of urban form on a child's travel mode to school. Transp Res Part A Policy Pract. 2007;41(1):69-79.

37. Mitra R, Buliung RN. Built environment correlates of active school transportation: neighborhood and the modifiable areal unit problem. J Transp Geogr. 2012; 20(1):51-61.

38. Zhu X, Lee C, Kwok O-M, Varni JW. Context-specific correlates of walking behaviors to and from school: do they vary across neighborhoods and populations? J Phys Act Health. 2011;8(suppl 1):S59-S71.

39. Repast. Repast agent simulation toolkit. Available at: http://repast.sourceforge.net/repast_3. Accessed April 5, 2014.

40. Jacobsen PL. Safety in numbers: more walkers and bicyclists, safer walking and bicycling. Inj Prev. 2003; 9(3):205-209.

41. Brüde U, Larsson J. Models for predicting accidents at junctions where pedestrians and cyclists are involved: how well do they fit? Accid Anal Prev. 1993;25(5):499509.

42. Leden L, Gårder P, Pulkkinen U. An expert judgment model applied to estimating the safety effect of a bicycle facility. Accid Anal Prev. 2000;32(4):589-599.

43. Forsyth A, Krizek KJ. Promoting walking and bicycling: assessing the evidence to assist planners. Built Environ. 2010;36(4):429-446.

44. Buehler R, Pucher J. Walking and cycling in Western Europe and the United States: trends, policies, and lessons. Available at: http://policy.rutgers.edu/faculty/ pucher/TRNWesternEurope.pdf. Accessed April 5, 2014. 45. Jago R, Macdonald-Wallis K, Thompson JL, Page AS, Brockman R, Fox KR. Better with a buddy: influence of best friends on children's physical activity. Med Sci Sports Exerc. 2011;43(2):259-265.

46. Smith AL. Perceptions of peer relationships and physical activity participation in early adolescence.J Sport Exerc Psychol. 1999;21:329-350.

47. Maturo CC, Cunningham SA. Influence of friends on children's physical activity: a review. Am J Public Health. 2013;103(7):e23-e38.

48. Salvy S-J, de la Haye K, Bowker JC, Hermans RCJ Influence of peers and friends on children's and adolescents' eating and activity behaviors. Physiol Behav. 2012;106(3):369-378.

49. Centers for Disease Control and Prevention. Barriers to children walking to or from school-United States, 2004. MMWR Morb Mortal Wkly Rep. 2005;54(38): 949-952.

50. Fesperman C, Evenson KJ, Rodriguez DA, Salvesen DA. Active transport to and from school: a comparative case study. Prev Chronic Dis. 2008;5(2):1-11.

51. Saelens BE, Sallis JF, Frank LD. Environmental correlates of walking and cycling: findings from the transportation, urban design, and planning literatures. Ann Behav Med. 2003;25(2):80-91. 